\section{ON CAPSULAR CATARACT, \&C. IMPRESSIONS EXPERIENCED BY PERSONS ON THE RECOVERY OF SIGHT.}

\section{By F. H. BRETT, Esq., F.R.C.S.E.}

LATE STRGEON TO THE GOVERNOR-GENERAL'S BODY-GUARD, BENGA SURGEON TO THE WESTERN OPHTHALMIC INSTITUTION, LONDON.

WHE: the profound and discerning Locke, in his "Essay on the Human Understanding," asserted that ideas were not innate, he meant, no doubt, that so far as the mind's intercourse, in its present condition, with all objects submitted to it, was concerned, its noble faculties were destined to be educated only by legitimate objects of excitation through the medium of the senses appointed for that purpose. His eccentric comparisons of the mind to a dark room, a blank sheet of paper, \&c., meant in reality nothing further.

It occasionally happens that in very extensive practice we have opportunities of illustrating this, in cases of restoration to sight of persons born blind, and also in cases of individuals who have known and distinguished colours; and "then (as Locke expresses it) cataracts shut the windows." If restored to sight many years afterwards, they are in precisely the same situation as though they had never seen before, having, no more than individuals born blind, the slightest recollection or idea of colours. All is to be acquired "de novo."

I will particularize the following from amongst several which have occurred to me.

No. 1.-The following is illustrative of the fact of all ideas of objects and colours having to be acquired, as well as a verification of the problem contained in the 8th section of the 2nd book of Mr. Locke, in his chapter on Perception. "Suppose a man born blind, and now adult, and taught by the touch to distinguish between a cube and a sphere of the same metal, and suppose the cube and the sphere placed on a table, and the blind man be made to see; (query: whether by his sight before he touched them he could now distinguish and tell which is the globe and which the cube?) to which the acute and judicions proposer answered-No."

A pandit, eighteen years of age, native of Saugor, was born blind; his mother states that she had kept him in a dark room until the 10th day after her confinement, when on taking him to the door and exposing his eyes to the light, she discovered the pearly appearance of the pupils peculiar to cataract; and she affirms that he has always been blind. $\mathrm{He}$ is intelligent and cheerful, and has been in the habit of finding his way about Saugor and the adjoining country for many years, frequently singing, of which he is very fond. He had little or no inclination to undergo the operation,--at least not sufficient to overcome the fear which he entertained. $\mathrm{He}$ could perceive the light, and had acquired the habit of rotating the head constantly in progression in a regular and curious manner to the right and left, with a rew, I imagine, of admitting the light to the retina obliquely between the circumference of the cataract and the inner edge of the iris. It was a long time before his relations could persuade him to submit to an operation. He had requested to be taken to me some months previous; was gratified at being told that he might be made to see like other people; but the slight inconvenience attending the introduction of a few drops of the solution of belladonna into the lids, and my holding the lids to try how they should be supported, annoyed him-and he said he would much sooner go home and eat his dinner. "What do I want with being restored to sight?" His mother likewise expressed her disbelief as to a person born blind being made to see. The principal pandit of the muhallah at length overruled the objections. The operation was performed on the 28th August. He complained of but little pain, and indeed there was scarcely any inflammation produced by the operation. He immediately became conscious of a considerable increase of light.

The eyeballs, as in all cases of congenital cataract, moved about without any control, which, together with a very prominent brow and much spasmodic action of the lids, offered some obstacles. So little irritation had occurred, that I operated, on the 30th of August, on the left eye, this operation resembling the former in every particular. No inflammation followed, but the right eye had become inflamed, in consequence of which his eyes remained bandaged for several days, and it became necessary to bleed him. He expressed himself as sensible of a remarkable change having taken place: the light was most distressing to him, and continued so for some time. On the eighth day the absorption had proceeded very satisfactorily: several substances of various colours were pre. sented to him. He could not recognise any of them until he had made himself acquainted with'them by the sense of touch.
He brought them very close to his eyes, moving his head in his accustomed peculiar manner. Whatever he attempted to reach, he always missed his aim. He expressed himself as highly gratified, and confident that he would see and know everything, but he did not like too much interrogation. On the 12 th day, he came to me again. The eyeballs were no longer rolled in their former vacant manner. He had acquired the power of directing the left eye, which had been most instructed, on objects, the right eye, from inflammation, having remained bandaged. A lady showed him her shawl: he said it was red, which was correct; but did not know what it was, until examined by the hand. The platform in front of the house was recognised as green, and his mother said he had been examining many things at home. The absorption of the cataract had proceeded, leaving two-thirds of the pupil of the left eye quite clear; some inflammation still in the right. He said he was no longer afraid of me, and that he would submit to anything I recommended. On the 16 th of September, he walked from the town to see me, accompanied by his mother. He had gained much information during his absence. The pupil of the left eye had become almost entirely clear. $\mathrm{He}$ said he had seen a great number of trees on the road, the lake, and a buggy passing by. He had made himself acquainted with several things. What is this?-A lota. This?-A pawn leaf. Which answers were correct. A small hookah was shown him: he touched it, and was told what it was; several things were then presented to him, and the hookah was a ain brought. He observed, "I cannot tell; you have submitted so many things to me, that I am confused, and forget their names." He felt it, and then exclaimed, it is the same hookah. Presently, it was shown him a third time: he recognised it, after having carefully viewed it from top to bottom, without touching. He observed a book, remarking that it was red; but he knew not that it was a book until told so. It was presented to him a few minutes afterwards, and he recognised both the colour and the book. He said he was extremely happy and gratified with all he saw. He followed me with his eyes as $I$ moved about the room, and pointed out the different positions $I$ took. He recognised distinctly the features of his mother's face. She hid it under her chadder; he laughed, and observed that she had done so, and turned his face away. He said, "I can see everything; all I want more, is time to learn what they all are; and when $I$ can walk about the town, I shall be quite satisfied." He could not ascertain whether anything was round or square, smooth or rough. He distinguished the following: some partridges, the cage, and the cup containing the water. The colour of their plumage he correctly stated; also the windows, the fields, the sky, a child in arms, \&c. On the 17 th, he again came to see me. He pointed out every feature in his mother's face, her hair, the colour of her dress, the different distances and positions which she purposely took, and when changing places with another woman, selected her out. He stated, that if I would bring the red book I showed him yesterday, he would recognise it. I accordingly brought him a red morocco book, but smaller; he said it was the book! At this period, his knowledge of the shapes of bodies, and their sizes, was very imperfect, especially the latter. He directed his hand straight to whatever things were now presented before him. The last time I saw him, a small ivory looking-glass, a papercutter, and a cut jelly-glass, were placed on the ground; they were shifted and changed, and he distinguished each respectively. He was much amused, and langhed heartily. I gave him the looking-glass, in which he noticed his face, and said it was like other people's, ach chha.

It will appear, therefore, that his judgment of distance, colours, motions, and positions, was very considerable. That of size and form was to be acquired more tardily.

At this period I quitted Saugor, and have heard nothing further of him.

No. 2.-The next is a similar instance of an individual who had never seen before-a Bralimin boy of ten years of age, residing at the Kherie Pass, near the Dehra valley.

A few days after the first operation, when the bandages were removed, the principal circumstance worthy of note was the confusion and embarrassment of the mind, arising from new and unaccustomed impressions, and the dazzling influence of light.

On the seventh day he had acquired some voluntary power over the ball of the eye, being able to steady it somewhat, and fix it on any object he wished to discern, but only for a few moments. He had, after repeated practice, acquired a knowledge of most colours, but it was not until the twenty-sixth day from the first operation that he could be said to have a tolerable acquaintance with the risible world. During this 
period, when the absence of pain and inflammation permitted, (for it was necessary for him to undergo several operations, ) the bandages were removed before and after sunset, and his attention was directed to men sometimes standing, sometimes moving; also to the tent, sky, trees, and their foliage, animals of different kinds, the colours, and figures, and motions of which he was able in time to discern.

There was no correspondence, however, for a long while, between the sight and touch, neither did he for several days direct his eyes straight to objects, so as to examine them minutely. At night he would contemplate the stars, the flame of a candle, and the features of my face, \&c. Debility, the necessary result of the treatment \&c. in a delicate frame, was one cause of the slowness of progress. As he gained strength by an improved diet, his vision greatly improved.

He was observed to take up various objects and notice them; latterly, $I$ was in the habit of calling him into my tent when at breakfast. He noticed the cups and saucers, and their patterns; chintz on the canvas; and he observed attentively a hookah, describing the bell (cut glass) as bright; noticed the snake, and mouth-piece (silver), and saw distinctly the smoke ascending.

On the 20 th of December, he walked several yards without assistance. A lady gave him a coloured chintz cap, with which he was much pleased, and he distinguished on it the colours of green and red, and the white ground. As his new sense could scarcely be said to have been fairly exercised more than fourteen days, further observations could not be made as to his judgment of distances, positions, forms, and motions.

No. 3.-A similar result, as far as phenomena, occurred in a boy of twelve years of age, though his acquirements were more rapid, from his natural mental intelligence being superior to the former individuals; the cause of his blindness was disease, soon after birth, from the small-pox. The nature of the operation being the formation of an artificial pupil opposite the outer transparent portion of the cornea, it is unnecessary to repeat the details, which are so similar to the preceding; and though he had seen for some weeks of his early existence, of course he had to acquire all de novo.

No. 4.-There are others who have been restored to sight who had lost it at a more advanced period of life-say five or six years of age and upwards; and who, when restored, exhibited peculiar phenomena more or less interesting in proportion to the degree of remembrance they may have possessed of their former vision. This was particularly remarkable in a young man of twenty-five years of age, the brother of the boy mentioned in case No. 2, who had become blind when only five years old, and which is remarkably interesting in a physiological point of view, as showing the power of the retina to preserve its susceptibility to light for twenty years, though not the only case recorded. There was certainly in this case a great approximation to the phenomena manifested in congenital blindness, but there was not that marked ignorance in recognising ojjects at first sight, nor that palpable want of correspondence between the touch and sight, though both existed to some extent.

I recollect restoring a man at Cawnpore, aged thirty-five years, who had been blind for a period of twelve years from the syphilitic iritis, causing closure of the pupils. This man, after an operation for artificial pupil, recognised, of course, everything perfectly the moment he was permitted to look about him. The interesting case described by Cheselden, and also those by Wardrop and others, are well known, but the above brief account of several occurring in Indian practice may nevertheless be not uninteresting to the profession.

Dorset-street, Portman-square, Aug. 1846.

\section{REVIEWS.}

A New Memoir on the Nervous System. By Marshall HaLl, M.D. London: Baillière. 1843. (PART III.)

Having now treated of the true Spinal Marrow in its anatomy and physiology, and in its relations to the diagnosis, pathology, and therapeutics of the diseases of the nervous system, we proceed, in conclusion, to some general considerations respecting the subject, such as the reasons which have retarded the appreciation and reception of the discovery by the profession, the share taken by others in making out the discovery, an estimate of its scientific rank, and its probable influence on the progress of medical science.

\section{Reasons for the tardy reception of the Discovery.}

There have been peculiar reasons why the spread of this discovery has lagged so singularly. In the first instance, the conduct of the Royal Society, under the influence of Dr. Roget, Dr. Wilson Philip, and Mr. Children, was a buffet of no ordinary kind. A discovery, which claimed to be great, and which would condescend to no lower designation, was placed under a bitter ban, when the Royal Society, the proper home of "natural knowledge," drove it forth as unworthy a place in its Transactions. The powerful bias thus created against it, prevented the fair play of the medical mind, and the matter was obliged to wait till it could be set right by that resilience which belongs to truth, and which is always dereloped by anything like injustice. Then, again, the notes of derogation proceeding from the Royal Society were taken up and re-echoed by several among the medical journals. The remarkable facts have been alluded to, that whereas in one journal, the British and Foreign Medical Review, numerous articles have appeared in its dispraise, not a single review of the subject has ever appeared in the Edinburgh Medical and Surgical Journal, and yet the latter accounts itself upon the title-page as a medium of discovery. The British and Foreign Review, and its writers, headed by Professor Alison, have ungraciously performed, with reference to the true spinal marrow, a part of that function in the formation of science which Professor Whewell calls "the discussion of ideas." Of many discoveries it has been affirmed that that which is new in them is untrue, and that which is true is not new; but in the journal in question, the physiology of the spinal marrow has been at one time new and untrue, at another, true, but old. However, it has at length silenced its own thunders by its own arguments, and dismissed all the reasonings which its own fertility could produce against the reception of the doctrines as far as it has understood them, but which is, after all, only in a limited degree. Mr. Whewell recommends us to be charitable to such minds, and says it is as ungrateful to despise them as it would be, if, in the case of a person preparing a telescope, we "should wonder at his stupidity in pushing the tubes of the eyeglass out and in so often." The misfortune is, that they may be pushed in and out while others would gladly be looking through the glass. The conduct of some other contemporaries of this discovery deserve a passing word. Dr. Wilson Philip, who has spent the greater part of his life in playing with experiments on thenervous system, has never mentioned ourauthor's name. Neither is the name of Marshall Hall to be found once in all the works of Bell. Such weakness on the part of Sir C. Bell cannot but be thought singular, and deplored; in the same way, we must deplore the weakness of this eminent man in dispraising, in the latter part of his life, physiologieal experiment, which had been the means of establishing the product of his own genius, and the importance of which, Harvey, the great Master in physiology, had defended and fortified beyond the power of cavil. Another cause for the slow reception of the reflex function has lain in the material studies of medical men. The tendency of the medical era has been towards a new form of humoralism; the studies of the times-morbid anatomy, pathology, and organic chemistry, are all material in their objects, and render men's minds inept to the study of the phenomena and the laws of action of a vital force or imponderable, such as the excito-motor power. Other reasons are, that very many have taken their views of this department of physiology from polluted sources: it is not unfrequent to see persons writing upon the matter, and dogmatizing upon its merits, who evidence by their productions, and candidly confess, that they draw their knowledge from the writings of partial reviewers rather than from the works of Dr. Marshall Hall himself. As an instance, we may observe that, in his Medical Notes and Reflections, Dr. Holland, who was on the Council of the Royal Society at the time Dr. Hall's memoir was blackballed, recommends his readers for information to the British and Foreign Review, against whose 